\title{
Opening Up Technologies to the Social: Between Interdisciplinarity and Citizen Participation Susana Nascimento, Alexandre Pólvora
}

\section{Introduction}

Our notion of opening up technologies is primarily linked to both a conceptual debate regarding the social contexts of artifacts and a more practical approach regarding past, present, and future options for designing, building, and using them. But ultimately, it points to questions about the social purposes that should guide technological development, about the social conditions under which artifacts are to be produced and used, about how all these factors contribute to configurations of macro and microscopic social structures, and about how we-as social and human scientists-might act upon these scenarios. Our key stances depart from the broad domain of science and technology studies (STS) where a few "openings" are already in motion with reference to understandings of technologies and their social connections. However, our paths cross and join other fields where different degrees of openness, currently in place, are encouraging and producing numerous levels of discussion and change in such disciplines as design, architecture, engineering, and computation, among others. By mixing contributions from such diverse sources, this article seeks to identify and set directions for further extensions of technological openness to social subjects, stakeholders, and platforms.

To reach our goal, we suggest approaching it from two cardinal directions: (1) interdisciplinary collaborations between social and human researchers and the myriad of people and institutions designing and building artifacts; and (2) the participation of citizens and communities in these processes. These routes are only two amid several others that currently contribute to the opening of technological grounds to social realms. Nonetheless, they become highlighted here because of their effectiveness and potential that has been demonstrated in recent years. They rarely correspond to two separate processes occurring at distinct moments, or in isolated projects or contexts. In addition, most endeavors that choose to follow either one, or a combination of both directions, don't always have the same levels of commitment, or even the same degrees of engagement with social researchers or lay publics, for 
1 Victor Papanek, Design for the Real World: Human Ecology and Social Change (Chicago, IL: Academy Chicago Publishers, 2009).

2 Victor Margolin and Sylvia Margolin, "A 'Social Model' of Design: Issues of Practice and Research," Design Issues 18, no. 4 (2002): 24-30.

3 See the special issue on socially responsive design, CoDesign 7, nos. 3-4 (2011).

4 François Jégou and Ezio Manzini, eds., Collaborative Services: Social Innovation and Design for Sustainability (Milan: Edizioni POLI.design, 2008).

5 Robin Murray, Julie Caulier-Grice, and Geoff Mulgan, The Open Book of Social Innovation (London: Young Foundation NESTA, 2010).

6 Authors such as Findeli have contributed to these new perspectives, countering the idea of isolated design systems and promoting the concept of the designer as stakeholder. See Alain Findeli, "Rethinking Design Education for the Twenty-First Century: Theoretical, Methodological, and Ethical Discussion," Design Issues 17, no. 1 (2001): 5-17.

7 Langdon Winner, The Whale and the Reactor: A Search for Limits in an Age of High Technology (Chicago, IL: University of Chicago Press, 1986), 12.

8 Albert Borgmann, Technology and the Character of Contemporary Life: A Philosophical Enquiry (Chicago, IL: University of Chicago Press, 1987), 35.

9 Don Ihde, Technology and the Lifeworld: From Garden to Earth (Bloomington, IN: Indiana University Press, 1990), 48.

10 Wiebe Bijker et al., eds., The Social Construction of Technological Systems: New Directions in the Sociology and History of Technology (Cambridge, MA: MIT Press, 1987). example. But all things considered, these two approaches point us toward technological openings where conceptual and practical convergences between the social and the technical not only are achievable in much broader ways, but also are central to adequately integrate the largest manageable number of stakeholders and to warrant sustainability at the broadest possible level throughout our built lifeworlds.

\section{Paths of Openness in Design and STS}

The notion of opening up technologies to the social plays a progressively larger role for design scholars and professionals. It's never redundant to retrieve Papanek's call for designers to move beyond market constraints toward more social and moral design that is closer to human needs, ${ }^{1}$ or Margolin's intention to redirect design to the needs of the poor, the aged, the disabled, and other disempowered groups. ${ }^{2}$ The value of social openness in design now assumes other positions-for instance, within the approaches of human-centered design, social design, or socially responsive design, ${ }^{3}$ where social issues, social impacts, and social change stand out. Furthermore, note the proposal that the concept of social innovation can support innovation driven by social goals, rather than private market, scientific, or technological requirements ${ }^{4}$ while combining top-down and bottom-up approaches. ${ }^{5}$ The openness in design is proceeding to larger spaces and seizing more opportunities to achieve wider results by altering more and more artifacts using what comes from the social. The focus on social design's involving, for example, continual references to marginalized groups or developing regions is now being increasingly directed to broader terrains regarding the conception, construction, and use of more artifacts and to the notion that the designer should be aware of its role within its target environment. ${ }^{6}$

From our standpoint in STS, the opening up of technologies can be equally traced to multiple works and discussions. In recent decades, several frameworks established-as common groundthe idea that all artifacts simultaneously embody and are transformed by social norms, values, and other economic, ecological, political, or cultural forces. Acknowledging in any given debate the social character of technology by itself and the social meaning of technical features thus became easier. Defining technologies as "forms of life,"7 "patterns," ${ }^{8}$ or "mediators" ${ }^{\text {"9 }}$ provides insightful notions to qualify their interferences in our modes of existence, in the sense that they mold the conditions for working, moving, and communicating. In pointing toward the openness of technologies, the focus has been less on the social origins and contexts of construction, ${ }^{10}$ and more on the political, moral, and ethical perspectives that attend to the social conditions brought about by technologies, demanded by them, and expected to emerge through 
11 Critical STS studies can be defined as "the confluence of research traditions that includes feminist/antiracist studies, critics of the technological society, radical science researchers, and various other scholars who are concerned with issues of social justice and democracy." David Hess, Science Studies: An Advanced Introduction (New York, NY: New York University Press, 1997), 113.

12 Edward Woodhouse and Jason W. Patton, “Design By Society: Science and Technology Studies and the Social Shaping of Design," Design Issues 20, no. 3 (2004): 6.

13 Dean Nieusma, "Alternative Design Scholarship: Working Toward Appropriate Design," Design Issues 20, no. 3 (2004): 13-23.

14 Among a variety of scholars and practitioners, see e.g., the pioneers Godfrey Boyle and Peter Harper, eds., Radical Technology (London: Wildwood House, 1976); Peter Dunn, Appropriate Technology: Technology with a Human Face (London: Macmillan, 1978); and Ernst Friedrich Schumacher, Small is Beautiful: A Study of Economics as if People Mattered (London: Sphere, 1974).

15 Ilse Oosterlaken and Jeroen van den Hoven, eds., The Capability Approach, Technology and Design (Berlin: Springer, 2012).

16 Nigel Whiteley, Design for Society (London: Reaktion Books, 1994).

17 John Thackara, In the Bubble: Designing in a Complex World (Cambridge, MA: MIT Press, 2005).

18 David Hess, "Ethnography and the Development of Science and Technology Studies," in Sage Handbook of Ethnography, Paul Atkinson et al., eds. (Thousand Oaks, CA: Sage, 2001): 240 them. This path mostly relates to critical STS studies, ${ }^{11}$ which try to reveal and counter cultural stereotypes, power relations, and patterns of social order that are embedded in technologies.

Looking directly at STS on design issues, we see that opening up of technologies to social grounds and actors came closer to views that "emphasize where design goes from here, and what it will take to reconstruct technologies more wisely and fairly." ${ }^{12}$ Views such as universal design, participatory design, ecological design, feminist design, socially responsible design, and appropriate design, ${ }^{13}$ with roots in the appropriate technology movement, ${ }^{14}$ have been deemed as essential inquiries in this domain, particularly regarding the social inequalities embodied in design practice and products. Another valuable perspective is the capabilities approach, which proposes that the guiding principle for technological innovation and engineering design should be the effective opportunities provided to people. ${ }^{15}$ Notions such as "design by society" or "designing for society"16 have indeed paved the way to change how and for whom technologies are designed. And they have done so through the traditional emphasis on the social needs of marginal groups and on the social contexts of developing countries under the goal of sustainable development, but also by moving into less peripheral fields through a renewed focus on a wider number of populations and artifacts..$^{17}$

Whether stimulated by practical exercises, such as those of socially responsive and inclusive design models, or animated by conceptual approaches, such as those offered by more critical STS perspectives, nearly all debates and experiments in opening up of technologies to social realms are indeed valuable and should be supported. Their aim generally follows what we deem as appropriate directions: (1) countering concrete biases that envision and produce artifacts in particular ways, (2) questioning unsustainable paths of producing and using specific artifacts, and (3) above all, permeating technical choices with wider social and cultural parameters. Nonetheless, there are yet some core paths we have to trek to better envision and work on the social conditions that certain artifacts might bring about, according to values of cultural sustainability, technological democracy, or scientific inclusiveness. These paths can be related to "postconstructivisms" on technologies, examining "ways in which [technologies] might be better constructed, with the criteria of 'better' defined explicitly and their contestability openly acknowledged as both epistemological and political." ${ }^{\prime 18}$ The challenges lie now in advancing the conceptual and practical trends of sustainable and equitable artifacts to include the social perspective from the start in the actual processes of reflection and construction of artifacts. We must extend the ongoing, opening transformations to other paradigms so that they can assimilate methods and concepts from the humanities and social sciences, while engaging more and more social groups and 
19 Robert Frodeman, Julie Thompson Klein, and Carl Mitcham, eds., The Oxford Handbook of Interdisciplinarity (New York, NY: Oxford University Press, 2010).

20 Valerie Brown, John Harris, and Jacqueline Russell, eds., Tackling Wicked Problems: Through the Transdisciplinary Imagination (London: Earthscan, 2010).

21 Helga Nowotny, "The Potential of Transdisciplinarity" (2006), www.helganowotny.eu/downloads/helga_nowotny_ b59.pdf (accessed September 20, 2012).

22 Günter Ropohl, "Philosophy of SocioTechnical Systems," Society for Philosophy and Technology 4, no. 3 (1994), http://scholar.lib.vt.edu/ejournals/SPT/ v4_n3html/ROPOHL.html (accessed September 20, 2012).

23 Peter Weingart and Nico Stehr, eds., Practising Interdisciplinarity (Toronto: University of Toronto Press, 2000).

24 Jesper Simonsen et al., eds., Design Research: Synergies from Interdisciplinary Perspectives (New York, NY: Routledge, 2010); Ina Wagner, Tone Bratteteig, and Dagny Stuedahl, eds., Exploring Digital Design: MultiDisciplinary Design Practices (London: Springer-Verlag, 2010).

25 Andrew Barry, Georgina Born, and Gisa Weszkalnys, "Logics of Interdisciplinarity," Economy and Society 37 no. 1 (2008): 22. actors to open up technologies by and for themselves. In the following sections, we articulate the pivotal directions that we see supporting the objectives identified: interdisciplinary platforms between social and technological experts and participatory processes involving citizens and communities.

\section{The Appeal of Interdisciplinary Connections}

Opening up technologies to the social can happen through a mutual engagement of practitioners and thinkers from disciplines such as design, sociology, architecture, philosophy, engineering, anthropology, and computation, among others. This engagement should resonate partially with other efforts to go beyond constraints of disciplinary knowledge ${ }^{19}$ in facing "wicked problems"complex issues with no complete definition and no single causal factor or simple solution. ${ }^{20}$ Here we note an overall need of interdisciplinarity in the process to fully acknowledge the social conditions that artifacts imply, from their design to their existence in everyday life. Opening up artifacts through the articulation of their technical features and social existences can only be realized when technical knowledge and social knowledge are mingled, with few to no restrictions. Interdisciplinary engagement isn't a simple disciplinary juxtaposition or simply shared teamwork; ${ }^{21}$ but in our view, it entails new modes of practical and conceptual collaboration that can integrate material qualities, building procedures, operation modes, aesthetic features, and technical orientations, with cultural contexts, political consequences, ethical scenarios, and convivial uses.

In this sense, disciplinary agents from both sides of the table must work together in interdisciplinary, overlapping ways that exchange ideas, models, and tools while sharing concerns and constructing debates about the material and social conditions of an artifact-prior to, during, and after its construction, use or disposal. An interdisciplinarity that focuses on the development of specific technologies is, in fact, a pressing need, considering that "specialized sciences (...) are unable to synthesize heterogeneous knowledge with regard to practical problems. So everybody cries for interdisciplinarity, but hardly anyone is aware of the theoretical point of interdisciplinary integration." ${ }^{22}$ Debates in STS have produced a broad range of understanding that now allows for practical developments in fields such as design; and in recent years, ${ }^{23}$ social sciences and humanities have been working on and around interdisciplinarity with design practices. ${ }^{24} \mathrm{We}$ are now seeing an increase in the number of interdisciplinary efforts "that cut across the boundaries between the natural sciences or engineering on the one hand, and the social sciences, humanities, or arts, on the other," ${ }^{\prime 25}$ that is, we are now witnessing bridging efforts which are opening up technologies to the social. 
26 Peter-Paul Verbeek, What Things Do: Philosophical Reflections on Technology, Agency, and Design (Philadelphia, PA: Pennsylvania University Press, 2000); Peter Kroes and Anthonie Meijers, "The Dual Nature of Technical Artifacts," Studies in the History and Philosophy of Science 37, no. 1 (2006): 1-4.

27 Anke Van Gorp and lbo Van Poel, "Deciding on Ethical Issues in Engineering Design," in Philosophy of Design: From Engineering to Architecture, Peter Vermaas et al., eds. (Berlin: Springer, 2008), 77-90.

28 http://www.utwente.nl/ctit/ research/projects/national/nwo/ overig/telecare_at_home.doc (accessed September 20, 2012).

29 Barbara Kovats, et al., "Current Information: SolarVillage Testfield, 6th ed., March 2011," www.tamera.org/fileadmin/PDF/SV_Currlnfo_ed6_32_en_web. pdf (accessed September 20, 2012).

30 Leila Dregger, "Grassroots Solar Solutions," Permaculture Magazine 42 (2004).
In the forefront of these efforts, we might find groups such as the Dutch 3TU Federation, which aggregates philosophers, sociologists, designers, engineers, and other applied scientists. ${ }^{26}$ One of the group's research lines examines the change of technical procedures via an interdisciplinary and applied approach developed by 3TU Centre for Ethics and Technology which includes the Technical and Philosophical departments of Delft, Eindhoven, and Twente Universities. Their openness efforts are visible in the incorporation of ethical aspects (e.g., moral acceptability and responsibility) and of social issues (e.g., health and safety, environmental quality, civil liberties and social justice) in technological R\&D..$^{27}$ In the project "Telecare at Home," ${ }^{28}$ for example, STS scholars such as Oudshoorn and Verbeek are collaborating with the Department of Computer Science and Biomedical Engineering at Twente, and the Roessingh Centre for Revalidation in Enschede. They are conducting a technology assessment exercise on design and use practices of telemonitoring devices-with the aim of developing normative evaluations that support scientists, engineers, and designers to address and resolve conflicting social norms in chronic care.

Likewise, outside academic realms, we find interesting examples of radical interdisciplinarity engaged with the technical and social elements of artifacts, such as the Tamera Cooperative, settled in an ecological village in Monte Cerro, southern Portugal. The cooperative's work is based on communitarian efforts between specialists from different backgrounds, including social scientists, engineers, architects, biologists, permaculture specialists, and artisans, with the broader aim of promoting sustainable ways of living. One of the main projects is the SolarVillage, ${ }^{29}$ planned and developed as a settlement with a largely self-sufficient supply of water, food production, and energy. The SolarVillage stands out as a very particular example in which technologies are opening up to the social, considering that it serves as a non-formal test bed for demonstration, training, and transfer of energy systems involving experts, non-experts, and volunteers from social to technological fields. ${ }^{30}$ Moreover, in Tamera, technical knowledge is integrated from the beginning with the values of sustainability and equity, and with the goals of local development that connect interdisciplinarity with other openings.

Projects, like the ones presented here, excel as examples in which experts from both domains discover how to work together with the intent of opening up artifacts to specific standards that favor social subjects and stakeholders. From ethical evaluations and responsible design, to sustainable practices, interdisciplinarity collaborations need to look into the complexities of our artifacts through a shared technical and social notion of what technology is, what it is for, and which methods should be used to improve its conception. This perspective should be clearly identified as a 
31 Barry, Born, and Weszkalnys, "Logics of Interdisciplinarity:" 35

32 Among many others, see Nigel Cross, ed., Design Participation (London: Academy Editions, 1972); and Douglas Schuler and Aki Namioka, eds., Participatory Design: Perspectives on Systems Design (Hillsdale, NJ: Lawrence Erlbaum, 1993).

33 Enid Mumford and Don Henshall, $A$ Participative Approach to Computer Systems Design (London: Associated Business Press, 1979); Pelle Ehn and Morten Kyng, "The Collective Resource Approach to Systems Design," in Computers and Democracy: A Scandinavian Challenge, Gro Bjerknes, Pelle Ehn, and Morten Kyng, eds. (Brookfield, VT: Avebury, 1987), 17-57.

34 Joan Greenbaum and Morten Kyng, eds., Design at Work: Cooperative Design of Computer Systems (Hillsdale, NJ: Lawrence Erlbaum, 1991); Lucy Suchman, "Consuming Anthropology," in Interdisciplinarity: Reconfigurations of the Social and Natural Sciences, Andrew Barry and Georgina Born, eds. (London: Routledge, forthcoming), www.lancs.ac. uk/fass/doc_library/sociology/Suchman_ consuming_anth\%20roploogy.pdf (accessed September 20, 2012).

35 See the special issue on participatory design, Design Issues 8, no. 3 (2012).

36 Andrew Barry, Political Machines. Governing a Technological Society (London: Athlone Press, 2001); Sheila Jasanoff, "Science and Citizenship: A New Synergy," Science and Public Policy 31, no. 2 (2004): 90-4; Philip Kitcher, Science, Truth, and Democracy (Oxford: Oxford University Press, 2001); Langdon Winner,Autonomous Technology: Technics-Out-Of-Control as a Theme in Political Thought (Cambridge, MA: MIT Press, 1977).

37 Frank Fischer, Citizens, Experts and the Environment: The Politics of Local Knowledge (Durham, NC: Duke University Press, 2000); Melissa Leach, lan Scoones, and Brian Wynne, eds., Science and Citizens: Globalization and the Challenge of Engagement (London: Zed Books, 2005).

38 Richard Sclove, Democracy and Technology (New York: Guilford Press, 1995), 181. significant view point in the processes intended to open up technologies, even calling to mind an "agonistic-antagonistic mode" engaging the "potential to transform the technological object from being merely an object or product into something which (...) is locally situated, socially contextualized, emotionally attached or encultured." ${ }^{31}$ These efforts can be expanded to include an engagement of the social in artifacts by modifying their content-that is, their descriptions, ends, and conditions-and enhancing the procedures that guide both their build and their use.

\section{From Citizen Participation to Open Community Initiatives}

The goal of opening up technologies, framed by interdisciplinary collaborations, entails close attention to all the particular contexts that inform the design, production, distribution, use, and discard of artifacts. These social, cultural, political, economic, and legal contexts permeate the artifacts while also integrating their content, and they change these same artifacts while equally being changed by their existences. In addition to all the possible disciplinary associations explored in the previous section, such close attention should be similarly pursued through closer contact with the people who actually use technologies, modify them, or even build new or alternative objects or systems. The focus on technical design and construction via interdisciplinary connections should thus be coupled with citizen empowerment, including their direct action upon artifacts and their daily experiences of them. The movement of opening up technologies to the social can benefit significantly from the active involvement of communities and citizens, not only in the sense of incorporating their knowledge and expectations under expert guidance, but also, in more radical pathways of engaging these communities and citizens to conceive technologies under new design paradigms that are able to integrate all actors.

A wide variety of scenarios of participatory design or cocreation have already been debated and tested, from the fields of design to those of STS. Participatory design developed along several paths $\mathrm{s}^{32}$-its roots primarily concerned with the values of workplace democracy and humanization, ${ }^{33}$ followed by key work on participatory forms and practices of systems development, ${ }^{34}$ and currently incorporating a variety of keywords including co-design, collaboration, mutual learning, situated design, among others. ${ }^{35}$ Giving a privileged role to citizens is also a fundamental part of the vast STS debate on the relationship between science, technology, and democracy, and the issues of social exclusion, public options, and values. ${ }^{36}$ Recent years have seen a "democratic turn" ${ }^{37}$ to ensure attention to citizen social needs and concerns and to "provide enhanced opportunities for fruitful cross-fertilization of ideas from one domain of social and technological experience to another." ${ }^{\prime 38}$ Both in design and in STS, 
39 Alan Irwin, "The Politics of Talk: Coming to Terms with the 'New' Scientific Governance," Social Studies of Science 36, no. 2 (2006): 299-320.

40 Nelly Oudshoorn and Trevor Pinch, eds., How Users Matter: The Co-Construction of Users and Technologies (Cambridge, MA: MIT Press, 2003); Eric Von Hippel, Democratizing Innovation (Cambridge, MA: MIT Press, 2005); Ellen Van Oost, Stefan Verhaegh, and Nelly Oudshoorn, "From Innovation Community to Community Innovation: User-Initiated Innovation in Wireless Leiden," Science, Technology \& Human Values 34, no. 2 (2009): 182-205.

41 For a description of the project, see http://socialtapestries.net/havelock/. See also Kevin Harris and Giles Lane, Social Tapestries: Conversations and Connections: Evaluation Report for the Ministry of Justice (Proboscis and Local Level, 2007), http://socialtapestries.net/ havelock/ST_Conversations_MoJReport. pdf (accessed September 20, 2012).

42 Giles Lane, "Urban Tapestries: Wireless Networking, Public Authoring and Social Knowledge," Personal and Ubiquitous Computing 7, no. 3-4 (2003): 169-75.

43 Richard M. Stallman, Free Software, Free Society: Selected Essays, 2nd ed. (Boston, MA: Free Software Foundation, 2010); Eric S. Raymond, The Cathedral \& the Bazaar, rev. ed., (Sebastopol, CA: O'Reilly, 2001).

44 Kerstin Balka, Christina Raasch, and Cornelius Herstatt, "Open Source Enters the World of Atoms: A Statistical Analysis of Open Design," First Monday 11, no. 14 (2009), www.uic.edu/htbin/cgiwrap/ bin/ojs/index.php/fm/article/view/2670 (accessed September 20, 2012).

45 Peter Troxler, "Commons-Based PeerProduction of Physical Goods. Is There Room for a Hybrid Innovation Ecology?" Presentation at the Third Free Culture Research conference (Berlin, October 8-9, 2010), http://wikis.fu-berlin.de/download/attachments/59080767/TroxlerPaper.pdf (accessed September 20, 2012).

46 It may be relevant here to recall the sense of craftsmanship offered by Sennett concerning the many technical and social dimensions of skill. Richard Sennet, The Craftsman (New Haven, CT: Yale University Press, 2009). bottom-up approaches are gaining ground, ${ }^{39}$ and in specific cases, such development even empowers users to make decisions about technical developments and views citizens and communities as technical innovators or initiators..$^{40}$

Opening up technologies potentially links in a double movement both the interdisciplinary platforms and the maximization of citizen contribution or invention. As an example in which citizen engagement stands at the center of interdisciplinary projects in design, the work at Proboscis, a UK artist-led studio that seeks to explore social, cultural, and creative issues and innovative associations between citizens, researchers, experts and policy makers, is noteworthy. The studio has conducted projects such as "Conversations and Connections," ${ }^{41}$ a collaboration with a community development consultancy and a residents' organization, in which concepts and tools were produced and used by residents to map and share local knowledge. The project was part of the program "Social Tapestries," which focused on public authoring by local groups and communities, and it was technologically supported by the Urban Tapestries platform, ${ }^{42}$ which combined mobile and web technologies with geographic information systems. In these projects, however, the main framework of the systems and artifacts still tends to be predetermined by the experts involved and thus is more closed off to early input from laypeople.

Other scenarios are emerging, however, that push the boundaries of public participation in technological development, with particular social groups and individuals taking up the roles of designers, builders, or makers, and enlarging the notion of technological openness. From open-source software movements, ${ }^{43}$ peer-to-peer movements and open design, ${ }^{44}$ to hackerspaces and digital fabrication labs, ${ }^{45}$ promising opportunities for conceiving and building virtual and material artifacts are available, with the support of large online and offline communities and with citizen participation from lay individuals to pro-amateur or specialized groups. In these trends, the rapport among social scientists, design experts, and citizens, as envisaged in this article, for example, certainly undergoes a number of changes as technologies are being invented, designed, and modified by a growing variety of actors according to a number of objectives and goals. From the outset, it allows more space for direct exchanges between all relevant actors in a given situation, with disciplinary expertise, ordinary needs, technical how-know, and local knowledge combined in stronger ways. ${ }^{46}$

As a recent trend, open-source hardware refers to "tangible artifacts-machines, devices or other physical things-whose design has been released to the public in such a way that anyone 
47 http://freedomdefined.org/OSHW (accessed September 20, 2012).

48 Elizabeth B.-N. Sanders and Pieter Jan Stappers, Convivial Design Toolbox: Generative Research for the Front End of Design (Amsterdam: BIS Publishers, 2012).

49 Clive Thompson, "Build It. Share It. Profit. Can Open Source Hardware Work?" Wired Magazine 16, no. 11 (2008), http://www.wired.com/techbiz/ startups/magazine/16-11/ff_openmanufa cturing?currentPage=all (accessed September 20, 2012). can make, modify, distribute, and use those things." ${ }^{\prime 47}$ The emergence of 3D printers, CNC cutters, and other tools for chip-making and 3D modeling has introduced cheaper possibilities for designing objects on a small scale and in smaller spaces. In this domain of citizen participation in technological development, the objects of open-source hardware projects are at the center of build-it yourself publications, such as Make magazine; of websites, such as Instructables.com or Thingiverse.com; or of online communities, such as OpenMaterials.org and P2P Foundation.net. As an example, consider the Open Source Ecology project, which is a network of farmers, engineers, and supporters that is developing the "Global Village Construction Set." The project participants are working on an open source, low-cost, high performance technological platform that allows for the DIY fabrication of 50 industrial machines, deemed by participants as the basis of a sustainable civilization with modern comforts. The machines include a 3D scanner, $50 \mathrm{~kW}$ wind turbine, aluminum extractor (from clay), bioplastic extruder, hay cutter, nickel iron batteries, and even an open source truck, all expected to have online tutorials or videos from groups working in different settings.

Setting up citizens as co-designers in the processes of opening up technologies entails deep collaborative models that often surpass lay or pro-amateur frontiers and that equally engage technical and social experts. ${ }^{48}$ For instance, some models, as illustrated here, first mobilize designers and social scientists who identify together the initial conditions for the artifacts in question, such as the required modes of construction and use, the production and business viability of technical and conceptual choices, the embedded values and purposes, and the previewed effects and unintended consequences. After this initial characterization, they usually work together with citizens to determine how citizens can participate, considering, for example, possible stages of their involvement, equitable participation methods, adequate exercises for individual and collective expression, and achievement of final consensus. However, other models, such as those emerging from open design and peer-to-peer movements, offer other rationales that allow for beginning-to-end processes of technical development that choose to include fewer experts, and more lay or semispecialized individuals or groups, through online communities and other forums. Whether "design is largely going to shift out from manufacturers to the communities, ${ }^{\prime \prime 9}$ certainly remains to be seen, and it calls for our utmost attention. But certainly the chance of devising technical experiments or prototypes in close cooperation with and in expanded scenarios shared by more and more users can allow for reflection on each phase of development, with decisions and visions articulated by a broader and less traditional spectrum of actors, using new standards and reaching toward needs and goals that are customized to specific contexts. 


\section{Conclusion}

Our argument rests in underlining the social in artifacts from our particular perspective as social scientists and urges movement toward the possibilities of their transformation through interdisciplinary and participatory efforts. What we have called here "opening up technologies to the social" rests mainly in new integrations of technologists, social scientists, and citizens in common projects of technical development, where objects and systems are created taking into consideration their material existence, social consequences, human values, and contextual conditions. Fruitful and promising theoretical and practical openings of technologies have contributed and are contributing to this understanding of artifacts. On the one hand, human and social thinkers and researchers offer conceptual frameworks on the topics under discussion, background social knowledge, and experience in interactions with social groups; on the other hand, designers, architects, artisans, and engineers offer conceptual frameworks, technical knowledge on objects' features and models, their performance, and their modes of functioning and use; and finally, citizens offer specific skills, local knowledge, interpretations on needs and experiences, and their own technical models and objects, playing their crucial part in determining the directions and ends of artifacts.

These openings are not new but are now occurring with increasing frequency in and between each of these three polesthat is, where technologists, social scientists, and citizens mainly operate. However, still missing are more numerous and complex bilateral connections between them and, ideally, more multilateral connections. For instance, a gap is still discernible between designers or technologists working on open source and peer-to-peer projects, social actors willing to participate in their operations, and human or social scientists at present engaged with such fields. The openings already visible aren't equitable or comparable between the poles. On the one hand, the technical transformations in materials, tools, and processes of production and the focus on users and technical pro-amateurs are more significant than the transformations in the mobilization of individual and collective actors, or in the interest of lay publics in integrating the technological process. On the other hand, these transformations in public participation seem to be greater than the transformations operated in the interdisciplinary connections between the social sciences and technical domains dedicated to open source, especially when those in the social sciences want to assume a proactive stance that pushes the limits of their traditional passive roles on technical processes of design and construction. 
In the face of opportunities already exposed, the movement should be to expand the scope of connections between the poles that, for the most part, tend to be restricted by their own sense of experimentation. Most successful or stimulating projects that are able to open up technologies to some degree, or even to fully integrate designers, technologists, social scientists, and citizens are still mainly occurring in constrained spaces, with small-scale resources or restricted public visibility. Most of the time, they appear as experiments or inquiries, and their artifacts are seen more as ingenuous gadgets, aesthetic pieces, or objects of curiosity than as real alternatives. Our final appeal concerns the necessity of pushing the technical openings already acknowledged inside design or STS into new and renewed spaces attached to interdisciplinarity and citizen participation, and to spread them in ways that could put all functioning at wider and more visible levels, while establishing openness as a desired standard in technical development. Here, the importance of linking the three mentioned poles again becomes evident. Changing artifacts from experiments to everyday objects in this opening paradigm can only occur when the objects are well-situated in social and cultural contexts-that is, when they result from adequate attention to all possible social and technical dimensions under the joint efforts of designers, technologists, human and social scientists, and citizens.

\section{Acknowledgements}

The authors would like to thank the Portuguese Foundation for Science and Technology (FCT-MEC) whose financial support made this research possible. 